* Doutor em Direito em 2005 pela Pontifícia Universidade Católica de São Paulo (PUC-SP).

Mestre em Direito em 2001 pela Universidade Federal do Ceará (UFC).

Especialista em Direito Processual Civil Individual e Coletivo em 2011 pela Faculdade Christus (CHRISTUS). Graduado em Direito em 1998 pela Universidade de Fortaleza (UNIFOR).

E-mail: alexandre.bruno@ terra.com.br

** Mestrando em Avaliação de Políticas Públicas pela Universidade Federal do Ceará (UFC).

Pós-Graduado em Direito e Processo do Trabalho em 2017 pelo Centro Universitário Christus (UNICHRISTUS).

Graduado em Direito em 2016pelo Centro Universitário Estácio de Sá.

E-mail: hawlysson@gmail. com

\section{Análise do Trabalho Escravo nas \\ Grandes Magazines: Uma LeITURA \\ Moderna ACErCa do Novo Modo de EXPLORAÇÃo}

\author{
Analysis of Slave Labor IN LaRge \\ DePARTMENT StORES: A MODERN \\ Reading of the New Mode Of \\ EXPLORATION
}

\begin{abstract}
Alexandre Antônio Bruno da Silva* Whenry Hawlysson Araújo Silveira**
\end{abstract}

Como citar: SILVA, Alexandre Antônio Bruno da; SILVEIRA, Whenry Hawlysson Araújo. Análise do trabalho escravo nas grandes magazines: uma leitura moderna acerca do novo modo de exploração. Scientia Iuris, Londrina, v. 22, n. 1, p.223-257, mar. 2018. DOI: $10.5433 / 2178-8189.2018 \mathrm{v} 22 \mathrm{n} 1 \mathrm{p} 223$. ISSN: $2178-8189$.

Resumo: O processo de globalização tem promovido significantes alterações no funcionamento das cadeias produtivas globais. Evidencia-se, como jamais visto, a exploração do trabalho pelo capital, materializada nas diversas formas de precarização das relações de trabalho. $\mathrm{O}$ presente estudo estrutura-se em dois eixos. O primeiro tem como objetivo analisar como as grandes empresas, objetivando reduzir os custos de produção e maximizar os lucros, se valem da exploração da mão de obra, desvinculando-se 
das responsabilidades perante os trabalhadores que fazem parte da sua cadeia produtiva. $\mathrm{O}$ segundo eixo busca analisar, de forma objetiva, em quais hipóteses estas empresas podem ser responsabilizadas pela exploração da mão de obra dentro das cadeias de produção de seus produtos. Por fim, evidencia-se o contexto em que se desenvolvem as políticas de combate ao trabalho escravo contemporâneo no Brasil, destacando os impasses até então encontrados na implementação dessas políticas.

Palavras-chave: Trabalho escravo contemporâneo. Responsabilidade social. Trabalho Forçado. Trabalho em condições degradantes. Exploração Infantil.

Abstract: Globalization is a process that has promoted significant changes in the inner workings of global production chains. Moreover, capital, which is embodied in various forms of labor relations, can and in some current cases exploits, even now, its labor force. Furthermore, this research is structured in two segments. The first analyzes how large companies use labor exploitation in order to reduce production costs and maximize profits, dissociating themselves from the responsibilities that they have in relation to their laborers that are an important part of their internal structure. The second investigates whether these companies can be held responsible for the exploitation of their employees - whom are part of their production 
network. In conclusion, this study demonstrates the context in which public policies fight contemporary slave labor in Brazil, highlighting the complexities of implementing these policies.

Keywords: Contemporary slave labor. Social responsibility. Forced Labor. Work in degrading conditions. Child Exploitation. 


\section{INTRODUÇÃO}

O trabalho possibilita ao homem concretizar seus sonhos, atingir suas metas e objetivos de vida, além de ser uma forma de expressão. Pode ser descrito como o desenvolvimento de uma habilidade que se externa através de um produto ao qual se percebe conectado.

Para Marx (1989, p. 22), “O conjunto das relações de produção forma a estrutura econômica da sociedade [...], o modo de produção da vida material condiciona o processo da vida social, política e espiritual em geral". Conforme asseveram Rusche e Kirchheimer (2004, p. 74), até mesmo as punições variam, quando os modelos de produção sofrem mutações. Portanto, necessário se faz uma rápida abordagem histórica acerca dos modos de exploração.

Após a chegada dos portugueses em território brasileiro, o escambo se torna a primeira relação entre portugueses e indígenas, tendo como principal atividade a extração de pau-brasil, madeira usada para a fabricação de tintura ${ }^{1}$.

A necessidade de introduzir rapidamente uma atividade econômica que gerasse mais renda levou os portugueses implantar os engenhos de cana-de-açúcar no nordeste brasileiro. Em meados do século XVI, a mão de obra dos nativos começa a ser substituída pela dos negros africanos, uma vez que esta demonstrava ser mais eficiente e barata (MARQUESE, 2006).

Conforme assevera Netto e Braz (2008, p. 67), "Nesse modo de produção, o trabalho era realizado sob coerção aberta e o excedente produzido pelo produtor direto (o escravo) the era subtraído mediante

$1 \mathrm{O}$ escambo consiste na troca de mercadorias ou serviços sem fazer uso de moeda. Referida modalidade de comércio foi comumente utilizada no contexto da exploração do pau-brasil, no início do século XVI. 
violência, real e potencial". Cumpre ressaltar que atualmente o regime de escravidão é tido por padrão como desumano e violador da dignidade da pessoa humana nos países civilizados, mas para a época, representou sinal de civilidade e libertação (FANON, 1979).

Com o advento da Lei Áurea², a previsão jurídica foi abolida no Brasil. Surge, portanto, novo modo de regulação das relações de produção. Essa transição ocorre quando, em certo período de desenvolvimento econômico-social, as forças materiais de produção se tornam incompatíveis com o modo de exploração utilizado. Conforme assevera Marx (1989, p. 14), “[...] ao mudar a base econômica, revoluciona-se, mais ou menos rapidamente, toda a imensa superestrutura erigida sobre ela".

Ao contrário do modelo escravagista, o modelo capitalista passa a reger as relações de exploração entre empregado e empregador, atribuindo valor ao potencial de trabalho e ao tempo utilizado para desenvolver determinada atividade. Dessa forma, todas as mercadorias utilizadas no mercado de trabalho capitalista passam a ser valoradas e sopesadas com base no binômio força de trabalho $x$ tempo de produção. Conforme Marx (2010), o trabalho sob o julgo do capital passa a alienálos no processo de produção, no intuito de que a mais valia seja extraída.

Outro fator que merece destaque no novo regime de exploração capitalista é a remuneração. Esclarece Marx (2010, p. 50-53) que a correlação de forças entre a classe trabalhadora e burguesa na disputa política de interesses opostos é fator determinante para a determinação dos salários. Desse modo, assevera que as remunerações e os lucros "estão em razão inversa um do outro. A cota-parte do capital, o lucro,

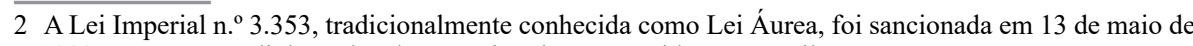
1888 e se tornou o diploma legal que extinguiu a escravidão no Brasil.

SCIENTIA IURIS, Londrina, v.22, n.1, p.223-257, mar.2018 DOI: 110.5433/2178-8189.2018v22n1p223 
sobe na mesma proporção em que a cota-parte do trabalho, o salário, cai, e inversamente." (MARX, 2010, p. 54).

Com o intuito de conter as diversas manifestações do trabalho escravo após o advento da Lei Áurea, surgem diversos dispositivos legais ${ }^{3}$ que buscam combater a permanência de condições análogas à escravidão no ambiente comum de trabalho. Não obstante a produção desse ordenamento específico, não há dúvidas que, mesmo em dias atuais, onde seu contexto é notoriamente camuflado, as condições desumanas dispendidas aos trabalhadores são manifestas.

A Constituição Federal de 1988, inspirada na Declaração Universal de Direitos Humanos, descreveu em seu artigo $1^{\circ}$, inciso III, que a dignidade da pessoa humana será fundamento do Estado Democrático de Direito. Posteriormente, em seu artigo $5^{\circ}$, inciso III, assegurou que ninguém será submetido a procedimento de tortura, tratamento desumano ou degradante.

Segundo o artigo 149 do Código Penal Brasileiro, considerase trabalho escravo a submissão do trabalhador a trabalhos forçados ou jornada exaustiva, compelindo-o a laborar em condições degradantes de trabalho, bem como restringindo, por qualquer meio, sua locomoção em razão de dívidas contraídas com o empregador (BRASIL, 2008).

Conforme assevera Thereza Gosdal (2007, p. 143), o trabalho análogo ao de escravo se tornou "uma categoria eminentemente política,

3 É possível afirmar que a gênese do trabalho se desenvolveu de modo paralelo à existência do ser humano em razão da necessidade de sobrevivência. A ele foi dada a capacidade de transformar o ambiente ao seu redor através da fabricação de objetos naturais. Entretanto, apenas a partir de meados do Século XVII as relações de trabalho passam a ser regidas de forma específica. Se considerarmos o Moral and Health Act, de 1802, na Inglaterra, que reduziu a jornada de trabalho dos menores para 12 horas, como a primeira experiência em regulação de natureza laboral e industrial a limitar o laissez-faire. Na realidade, antes mesmo destas experiências reguladoras estatais, o exercício da autonomia coletiva como fonte de direitos já se havia estabelecido, mesmo sem o reconhecimento do Estado, já que a atividade sindical começou durante os primeiros anos da Revolução Industrial, no final do século XVIII, e foi combatida pela Doutrina da Conspiração, sobretudo nos países anglo-saxões. 
sustentada sob toda a sorte de trabalho não-livre. "[...] são maus-tratos, condições de trabalho, de remuneração, de transporte, de alimentação e de alojamento que não condizem com as leis e costumes." Portanto, trabalho em condições análogas à de escravo é o gênero, do qual o trabalho forçado e o trabalho degradante são espécies.

Diferente do período escravagista, o trabalho em condições análogas à de escravo não mais se utiliza das ferramentas coloniais de repressão. Em que pese não mais se falar em senzalas ou em instrumentos ostensivos de castigo, como troncos e correntes, atualmente é possível notar que as condições análogas à de escravo estão presentes no mundo do trabalho, sobretudo nas grandes magazines, responsáveis por regular grandes cadeias de produção ${ }^{4}$.

Segundo o Sindicato Nacional dos Auditores Fiscais do Trabalho (SINAIT), no ano de 1995, o Brasil se tornou um dos primeiros países do mundo a reconhecer a permanência do trabalho em condições análogas à escravidão.

Ressalte-se que, apesar do Brasil possuir uma das mais protetivas legislações trabalhistas do mundo e ser adepto de diversos tratados internacionais ${ }^{5}$ que buscam erradicar a escravidão, a mera positivação de direitos não se mostra suficiente para tornar efetiva a proteção do trabalhador. É de extrema necessidade a intensificação da fiscalização e o cumprimento dos dispositivos que os regula.

4 Na visão de Karl Marx, o trabalhador tornou-se uma mercadoria - barata, suscetível de desvalorização. $\mathrm{Na}$ atualidade não é diferente, o trabalhador é submetido a condições análogas à escravidão e devido as necessidades vitais à sua sobrevivência, tende a compactuar com todas as condições que lhes são impostas. Conforme atrai para si os fenômenos naturais da vida (envelhecimento, doenças ou deficiências), seu valor tende a cair consideravelmente.

5 Os mais variados diplomas internacionais de proteção ao trabalhador derivam das convenções da Organização Internacional do Trabalho. Dentre os diversos tratados ratificados pelo Brasil, merece destaque as convenções 29 e 105 que tratam da eliminação do trabalho forçado ou obrigatório, convenções 87 e 98 que tratam da proteção ao direito sindical e negociação coletiva. Convenção 100 e 101 que tratam da igualdade de acesso e permanência no ambiente de trabalho. Convenções 138 e 182, que versam sobre a erradicação do trabalho infantil. 
Segundo Braga (2014), “ainda estamos caminhando a passos lentos em direção à abolição do trabalho escravo no mundo". Todavia, não se pode desacreditar nas mudanças, devendo-se a todo custo manter de forma contínua a busca pela efetiva erradicação das condições análogas à de escravo.

Sabendo que o modo de exploração varia nos diversos setores da economia, buscar-se-á analisar, no tópico seguinte, as diversas formas de manifestação do trabalho em condições análogas à de escravo na sociedade, com o escopo de demonstrar as deficiências existentes, bem como a necessidade da efetiva erradicação desse tipo de exploração que ainda hoje subsiste.

\section{AS FORMAS DE MANIFESTAÇÃO DO TRABALHO EM CONDIÇÕES ANÁLOGAS À DE ESCRAVO NAATUALIDADE}

Ao longo dos últimos anos, os modos de exploração têm se diversificado dentro das diversas atividades econômicas. Nesse passo, tem-se que a economia, a globalização, o crescimento das migrações e o desenvolvimento tecnológico acelerado são os fatores preponderantes para a persistência do trabalho em condições análogas à de escravo. Conforme afirma Schernovski (2014), a ocorrência desses fatores corrobora para a desvalorização do trabalho e das pessoas, in verbis: "A escravidão está inteiramente reproduzida pelas atuais condições da economia - desemprego tecnológico, crescimento das migrações e redução ao absurdo da remuneração de atividades tradicionais, geralmente tecnologicamente atrasadas."

As diversas formas de escravização se estendem por todo o globo terrestre e engloba desde os países desenvolvidos aos que ainda 
não alcançaram uma perspectiva de crescimento. Um mercado flexível ascende e se adequa rapidamente às mudanças, por isso sua rápida $\mathrm{e}$ frenética transformação. Em decorrência desses efeitos, as técnicas adotadas pelo Estado muitas vezes perdem sua eficácia.

Dados estatísticos do Sindicato Nacional dos Auditores Fiscais do Trabalho (SINAIT) colhidos no segundo semestre de 2016, revelaram que o número de trabalhadores que são submetidos a estas práticas ainda é alto e tem crescido nos grandes centros urbanos, sobretudo em atividades terciárias ${ }^{6}$, como construção civil e indústria têxtil. Na área rural, a exploração se dá massivamente na pecuária, na agricultura, nas carvoarias e madeireiras.

Contextualizando a compreensão desenvolvida, Nunes (2005) aponta que:

A degradação do explorado inicia-se ainda em sua localidade de origem, onde não possui as mínimas condições de subsistência. Vê seus familiares passando necessidade, quando não se encontram adoentados. No município, não enxergam a mínima expectativa de trabalho. O homem não consegue vislumbrar condições de melhoria para si e para seus familiares. Torna-se assim, vulnerável às promessas feitas pelos "gatos". O trabalhador vê à sua frente a seguinte opção: permanecer em sua cidade, sem qualquer expectativa, ou tentar sorte melhor em outras regiões, ainda que corra o risco de ver frustrada sua esperança. Quem sai, na verdade, queria permanecer, mas não fica, pois continuar é aceitar a dor que lhe corrói.

Ocorre comumente no Brasil a sujeição de trabalhadores pobres aos intermediários que, por sua vez, oferecem melhorias de vida, fundadas

6 Em uma visão macro, os trabalhadores pertencentes a estas atividades são analfabetos e desprovidos de uma educação formal. Em sua grande maioria, são trabalhadores necessitados, com pouca noção de seus direitos e que em razão da necessidade de sobrevivência, não têm outra escolha que não seja compactuar com as condições impostas pelo empregador. 
em falsos contratos. Ao serem levados para esses lugares distantes e isolados, esses trabalhadores são submetidos a uma vida de servidão por dívida e precarização do ambiente de trabalho.

Para Brito Filho (2017), o trabalho em condições análogas à de escravo se divide em duas grandes espécies: o trabalho forçado e o trabalho em condições degradantes. Os casos específicos estariam ligados a estas espécies como micro espécies de um sistema. Nada impede, portanto, a cumulação destas no mesmo ambiente de trabalho.

Nos tópicos seguintes, serão analisadas, de modo mais aprofundado, as diversas formas de manifestação do trabalho em condições análogas à de escravo, encontradas atualmente pelas grandes magazines para a exploração da mão de obra. Propõe-se, em conjunto com dados estatísticos, uma análise crítica que aborda as fragilidades ainda existentes no tocante a proteção do trabalhador.

\subsection{Trabalho forçado}

De acordo com Schernovski (2014), a modalidade de trabalho forçado pode assumir diversas faces no ambiente de trabalho. Entretanto, referida modalidade é caracterizada comumente pela coerção de uma pessoa sobre outra, para que esta realize determinadas tarefas sob a imposição de severas penalidades, caso a ordem não seja cumprida.

Importante conceituação foi dada pelo artigo $2^{\circ}$, item 1 , da Convenção $\mathrm{n}^{\circ} 29$ da Organização Internacional do Trabalho (OIT). Segundo o texto convencional, o "trabalho forçado ou obrigatório" designará todo trabalho ou serviço exigido de um indivíduo sob ameaça de qualquer penalidade e para o qual ele não se ofereceu de espontânea vontade". Desse modo, duas características podem ser extraídas dessa 
modalidade de trabalho escravo: o uso da coação e a negação da liberdade? .

A violação à liberdade, como componente substancial da micro espécie do trabalho forçado, é característica marcante dessa modalidade de exploração. Não bastasse a violação aos princípios da dignidade da pessoa humana, da legalidade, da isonomia, dentre muitos outros que integram o rol de direitos fundamentais, a negação da liberdade pelo método coercitivo do empregador é fator que o difere das outras modalidades de exploração.

Mesmo séculos após a abolição formal da escravidão, algumas semelhanças com os métodos coloniais podem ser encontradas na contemporaneidade. No atual cenário do trabalho forçado, observamse algumas características, como intensas jornadas laborais e coações morais, que trazem à memória os métodos arcaicos de exploração. Nesse modelo, o obreiro não mais pode deliberar de acordo com sua própria vontade acerca do consentimento de sua permanência no trabalho.

Por outro lado, o trabalho análogo à condição de escravo também pode se manifestar através de trabalhos em condições degradantes, conforme se verá adiante.

\subsection{Trabalho em condições degradantes}

O trabalho em condições degradantes não é tão simples de ser conceituado. Para que seja configurada a existência de trabalho forçado, é necessário que seja verificada a existência de restrição da liberdade, sobretudo através do uso de coação. No entanto, para a configuração do

7 Afirma a OIT que, "Embora possam variar em suas manifestações, as diversas modalidades de trabalho forçado têm sempre em comum as duas seguintes características: o recurso à coação e a negação da liberdade" (ORGANIZAÇÃO INTERNACIONAL DO TRABALHO, 2001). 
trabalho em condições degradantes, faz-se necessário a concentração de elementos que tornam as condições do ambiente de trabalho precárias. Para Brito Filho (2017), a dificuldade em conceituar reside no largo alcance do que poderia ser considerada uma condição degradante de trabalho, conforme se depreende logo abaixo:

Seria simples, por exemplo, dizer que um trabalho, mesmo que exercido em condições duras, como o dos lavradores no campo, não seria considerado como em condições degradantes se os trabalhadores tivessem a adequada proteção para o seu exercício; tivessem os seus direitos trabalhistas resguardados, incluindo aí jornada de trabalho normal, bem como tivessem condições razoáveis de moradia, alimentação e higiene, e fossem respeitados. Também é fácil definir trabalho em condições degradantes quando se utiliza, ainda negativamente, o princípio que fixa o mínimo de direitos do homem-trabalhador: a dignidade humana. Nesses termos, considera-se trabalho em condições degradantes aquele em que não são respeitados os direitos mínimos para o resguardo da dignidade do trabalhador.

Com essa compreensão, é possível conceituar o trabalho em condições degradantes como aquela atividade laboral exercida sem que existam condições mínimas de higiene, saúde, segurança, habitação, respeito e alimentação. Por assim dizer, na falta de um desses elementos, estaria configurada a modalidade de trabalho em condições degradantes.

Ambas as modalidades de exploração advêm principalmente do tráfico de pessoas, decorrente da imigração ilegal e das práticas irregulares de captação de mão de obra. Os trabalhadores sequer encontram tempo para buscar um futuro melhor. As dificuldades mais recorrentes que envolvem a parcela de trabalhadores explorados são o preconceito e a 
fome.

\section{A NOVA ROUPAGEM dO TRABALHO ANÁlogo AO DE ESCRAVO}

Segundo o SINAIT, desde que o Brasil reconheceu a existência de trabalho escravo, em 1995, mais de 50 mil trabalhadores nessas condições foram resgatados pelos Auditores Fiscais do Trabalho até o ano de 2015. No entanto, em 2016, não há sequer um dos responsáveis preso. Dos poucos condenados, nenhum deles cumpriu pena até o fim (SINAIT, 2016).

Em janeiro de 2004, três auditores fiscais e um motorista do Ministério do Trabalho foram assassinados, no evento que ficou mundialmente conhecido como "a chacina de Unaí". Os auditores trabalhavam na fiscalização de fazendas nesse município e suspeitavam da contratação irregular de trabalhadores para a produção de feijão. Muito embora o Tribunal Regional Federal de Minas Gerais tenha condenado os responsáveis pelo mando do crime e pela contratação dos pistoleiros, não há, sequer, registro de prisões efetuadas ${ }^{8}$.

Segundo a Comissão Regional sobre Trabalho Escravo do Tribunal Regional do Trabalho da 10 $0^{\text {a }}$ Região (TRT10), a crescente exploração de mão de obra se dá substancialmente pelo crescimento desse sentimento de impunidade. Para o Presidente da Comissão, quando o empregador submete o trabalhador a condições forçadas ou degradantes, está apostando na impunidade. (BRASIL, 2014).

Uma auditoria realizada pelo Ministério do Trabalho e Emprego

8 Além dos fazendeiros, estavam envolvidos na chacina os irmãos Antério Mânica, exprefeito de Unaí, e Norberto Mânica, bem como os empresários Hugo Alves Pimenta e José Alberto de Castro. (MELLO, 2017). 
(MTE) à sessenta e sete fornecedores da empresa Zara no ano de 2016, mostrou 433 irregularidades por todo o Brasil. Dentre elas, pode se destacar a supressão de salários e excesso na carga horária, ambos caracterizando a modalidade de trabalho forçado. De igual modo, as oficinas subcontratadas por esta empresa para atuar na confecção de peças foram atuadas cinquenta e duas vezes por manter condições análogas à escravidão, dentre eles, a servidão dos trabalhadores por dívidas contraídas. ${ }^{9}$

Responsáveis por movimentar um alto mercado de consumo, as indústrias têxteis comumente se utilizam da exploração da mão de obra para obter altos lucros. Segundo pesquisa divulgada pelo jornal Al Jazeera, a exploração de trabalho escravo no mercado da moda é constante.

Os casos mais recorrentes foram encontrados nos estados de São Paulo e Rio de Janeiro, uma vez que, por seu dinamismo e desenvolvimento econômico acentuado, atraem imigrantes de países vizinhos. Segundo o jornal acima, o agitado setor têxtil paulista conhecido como "Brás" alimenta um enorme mercado de consumo, ao passo que concentra condições precárias indicativas da ilegalidade e da falta de segurança que os trabalhadores estão a enfrentar.

Já no Rio de Janeiro, pesquisadores e profissionais da moda se reuniram recentemente para discutir métodos de combate à exploração nas cadeias produtivas no mercado da moda. Segundo a Procuradora do Trabalho Guadalupe Couto, é inconteste a subsistência de exploração de trabalho na indústria têxtil, sobretudo nas grandes grifes, responsáveis por movimentar um alto mercado de consumo com preços competitivos. (AGÊNCIA BRASIL, 2017). A necessidade de mão de obra barata leva

9 Para estes e outros dados estatísticos acerca da exploração dos trabalhadores na Grife Zara (MAIA, 2014). 
os trabalhadores a serem submetidos a condições degradantes, como ocorreu recentemente com diversas grifes de auto padrão autuadas. ${ }^{10}$

Os principais alvos desse setor são os imigrantes, atraídos pelo desenvolvimento e possibilidade de melhoria de vida. De acordo com o Ministério do Trabalho, em torno de trezentos mil bolivianos residem em São Paulo, 90\% deles, laboram em indústrias têxteis. O questionamento mais intrigante diz respeito a quantos destes estão submetidos ao regime de trabalho em condições análogas à de escravo. Compensação pelo mantimento e pelo treinamento recebido são algumas das condições impostas pelos empregadores aos imigrantes, conforme foi relatado por um casal boliviano recém liberto (ALJAZEERA, 2016).

Conforme expressa o representante da Organização Internacional do Trabalho (OIT) no Brasil, muitas vezes não é possível localizar tais formas de exploração, pois, em muitos casos, a pessoa mora e trabalha no mesmo local. Como a casa se constitui como asilo inviolável, não há possibilidade constante de ingresso, bloqueando uma fiscalização mais precisa (RIBEIRO, 2017).

Conforme ressalta Renato Bignani (2017, p. 34), essa prática não é recente. Segundo o autor, a alienação dos trabalhadores em células de residência é denominada sweating system. Mantendo células de trabalho semelhantes a residências, não há sequer controle das jornadas de trabalho. O ambiente se torna propício para quaisquer formas de exploração, tais como ambientes degradantes e insalubres, trabalho infantil, servidão por dívida, assédio moral e sexual.

Segundo estudos de campo realizados pela Comissão Pastoral de Terra, as regiões Nordeste, Norte e Sudeste, pioneiras no desenvolvimento

10 Algumas grifes nacionais, como Marisa, Pernambucanas, Renner, Les Lis Blanc - e, recentemente, até a marca internacional Zara, foram autuadas por manter condições de trabalho escravo (ALJAZEERA, 2016). 
econômico do País e grandes alvos de imigração, são as que mais exploram mão de obra. Demonstraram, ainda que, em medidas de fiscalização regular, o número de trabalhadores resgatados por região é proporcional à quantidade de trabalhadores em que são explorados, conforme se depreende dos gráficos abaixo ${ }^{11}$. Os estudos foram realizados com base em 766 casos detectados pela Comissão no ano de 2016.

Gráfico 1 - Exploração Mão de Obra por Região.

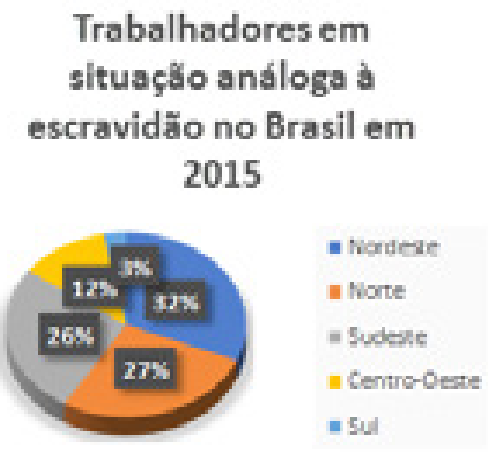

\section{Trabalhadores libertados no Brasil em 2015}

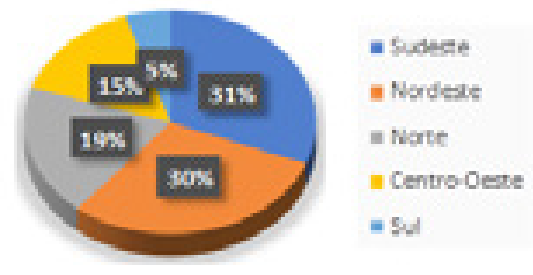

Fonte: Adaptado de Gandra (2017).

Como verificado até o presente momento, o combate não deve ser realizado apenas com medidas imediatas, ou se torna ineficaz. Devem ser propostas políticas específicas de combate a serem exercidas de forma gradual e sistemática. Se o trabalhador libertado volta para a mesma situação de miséria em que se encontrava antes, as chances de ser explorado novamente são altas.

11 Elaboração própria com base nos dados colhidos pela Comissão Pastoral de Terra e SRTE. Os estudos foram realizados no ano de 2016. Referências inclusas. 


\section{MECANISMOS DE COMBATE AO TRABALHO ANÁLOGO À ESCRAVIDÃO}

Conforme abordagem introduzida no preâmbulo do presente trabalho, diversos dispositivos constitucionais e infraconstitucionais entraram em vigor com o objetivo de proibir e punir aqueles que promovem o trabalho em condições análogas à de escravo. Além dos já citados dispositivos ${ }^{12}$, diversos outros estão presentes em todo o ordenamento jurídico e buscam assegurar a liberdade dos trabalhadores ${ }^{13}$.

Como afirmado em momento anterior, os dispositivos legais se mostram insuficientes para a erradicação dessas condutas. Essa situação é agravada pela ausência de políticas públicas de combate ao trabalho escravo. Nesse contexto, os órgãos fiscalizadores assumem vital importância.

O Movimento de Ação Integrada (MAI) busca preencher essa lacuna. Segundo o Sindicato Nacional dos Auditores Fiscais do Trabalho (SINAIT), os auditores fiscais buscam preencher essa lacuna. Muito embora ainda haja deficiências, os programas de qualificação e alfabetização dos egressos do sistema escravagista se tornam "portas de saída" desse regime.

Além do SINAIT, o MAI agrupa diversos outros órgãos, como a Organização Internacional do Trabalho, o Conselho Nacional de Justiça

12 Artigo $1^{\circ}$, inciso III, artigo $5^{\circ}$, inciso III da Constituição Federal e artigo 149 do Código Penal.

$13 \mathrm{O}$ artigo $5^{\mathrm{a}}$ da Constituição Federal preconiza que todos os brasileiros e estrangeiros residentes no Brasil são iguais perante a lei e têm garantidos direitos à isonomia, à liberdade, à segurança, entre outros. Ainda na esfera Constitucional, a Emenda Constitucional $n^{\circ} 81 / 2014$ alterou o texto do artigo 243, que passou a prever que, em propriedades rurais ou urbanas onde forem constadas ocorrências de casos de trabalho escravo, haverá expropriação para fins de reforma agrária e de moradia popular. O Código Penal brasileiro, em seu Título IV, dispõe ainda sobre os crimes contra as organizações de trabalho, prevendo sanções a quem atentar contra a liberdade de trabalho, frustrar direitos assegurados em leis trabalhistas ou aliciar trabalhadores mediante fraude, conforme se extrai dos artigos 197, 203 e 206 do mesmo diploma legal. Por fim, o diploma celetista buscou reduzir, coibir e punir os empregadores que venham, eventualmente, a violar condições probas de trabalho, de modo que submetam os obreiros a trabalhos forçados e/ou a condições degradantes de trabalho, conforme assevera os artigos 75 e 120 da Consolidação das Leis Trabalhistas.

SCIENTIA IURIS, Londrina, v.22, n.1, p.223-257, mar.2018 DOI: $110.5433 / 2178-8189.2018 v 22 n 1$ p223 
(CNJ), o Ministério Público Federal (MPF), o Ministério Público do Trabalho (MPT), o Tribunal Superior do Trabalho (TST), a Secretaria de Direitos Humanos (SDH), o Ministério do Trabalho e Emprego (MTE), além de diversas associações e Organizações Não Governamentais (ONGs) que atuam na prevenção e repressão da exploração (SINAIT, 2016).

No ano de 1995, dois grupos essenciais foram criados com o intuito de combater a precarização no ambiente de trabalho. O objetivo poderia ser descrito em poucas linhas: erradicar a exploração da mão de obra através de fiscalizações e inspeções periódicas. Pelo Decreto 1.538/95, foi criado o Grupo Interministerial para Erradicação do Trabalho Forçado (GERTRAF).

Em 14 de junho do mesmo ano, é emitida a Portaria de ${ }^{\circ} 550$, criando um dos grupos de combate que atua com maior intensidade dentre os existentes atualmente: o Grupo Especial de Fiscalização Móvel (GEFM). Ligado à Secretaria de Inspeção do Trabalho (SIT) do Ministério do Trabalho - o GEFM é formado por auditores fiscais do trabalho, procuradores do Ministério Público do Trabalho e policiais federais, que atuam no combate direto à exploração do trabalho, na apuração de denúncias e nas operações de resgate em campos específicos de exploração (LIMA; SURKAMP, 2012, p. 57).

Com o intuito de evitar que produtos oriundos do trabalho análogo ao de escravo sejam comercializados, foi criada outra política relevante: o Pacto Nacional pela Erradicação do Trabalho Escravo, composto pelo Comitê de Coordenação e Monitoramento do Pacto Nacional pela Erradicação do Trabalho Escravo. O Comitê é composto por diversos institutos e organizações que atuam em parceria. Entre elas, estão a Organização Internacional do Trabalho (OIT), a Comissão 
Pastoral de Terra e a Comissão Nacional de Erradicação do Trabalho Escravo (CONATRAE) (CANAL RURAL, 2017).

Mesmo que não haja controvérsia acerca da importância das instituições fiscalizadoras para a coibição desse tipo de exploração, os dados obtidos pelas recentes pesquisas demonstram que o número de agentes fiscalizadores tem caído nos últimos anos. O número de auditores fiscais do trabalho é pequeno e tem influenciado diretamente no número de resgates que são realizados. Se não há busca pela exploração, como ela pode ser constatada?

Uma pesquisa realizada pela Superintendência Regional do Trabalho e Emprego no Ceará (SRTE/CE) no início de janeiro divulgou que o número de trabalhadores resgatados caiu $96 \%$ com fiscalização menor no Ceará. O número de trabalhadores resgatados em condições análogas à de escravo passou de 70 casos em 2015 para apenas três em 2016, uma redução de 95,7\%. Ainda segundo o estudo, $83 \%$ dos trabalhadores resgatados possuíam faixa etária entre 18 e 44 anos. Desses, $33 \%$ são analfabetos e $39 \%$ sequer concluíram o ensino fundamental (G1, 2017). 
Tabela 1 - Trabalhadores resgatados no Ceará - SRTE ${ }^{14}$

Ano Número de Resgates

$2006 \quad 88$

$2007 \quad 19$

2008192

200920

201396

$2014 \quad 68$

$2015 \quad 70$

$2016 \quad 3$

Fonte: G1 (2017).

Em recente pesquisa realizada pela Divisão de Fiscalização para Erradicação do Trabalho Escravo do Ministério do Trabalho, a redução dos resgates se estende a todo o território nacional. Dados parciais apontam que mais de 660 trabalhadores foram resgatados pelos grupos móveis de combate ao trabalho escravo em 2016, representando uma queda de 34\% em relação aos 1.010 trabalhadores resgatados no ano de 2015. Apenas no ano de 2000 o número de resgates foi menor, atingindo a marca de 516 resgates (CANAL RURAL, 2016). 
Gráfico 2 - Trabalho escravo no Brasil

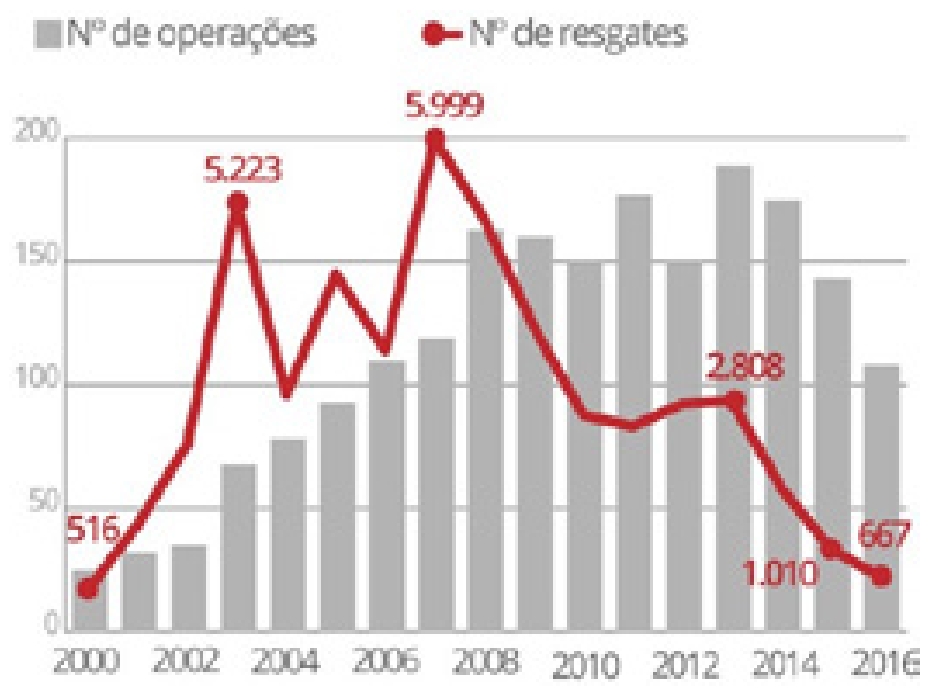

Fonte: G1 (2017).

Segundo o coordenador da Campanha de Prevenção e Combate ao Trabalho Escravo da Comissão de Proteção ao Trabalhador (CPT), a redução do número de resgates está diretamente ligada a uma redução no número de fiscalizações. Nas últimas décadas, em torno de 261 estabelecimentos foram fiscalizados por ano, em detrimento de 158 fiscalizações em 2016. Segundo o coordenador, pelo menos mil fiscais estão faltando no plano nacional para conter o aumento da exploração (VELASCO; REIS, 2017).

Esse fator, contudo, deve ser analisado com cautela e promovido pelo poder público. Se não há fiscalização, o trabalhador explorado 
não se manifesta por si mesmo, uma vez que sequer compreende sua condição de escravo. Com mais auditores fiscais atuando, maiores serão as fiscalizações, ocasionando um aumento no número de resgates.

\subsection{Da necessária publicidade da "lista suja" pelo trabalho escravo}

No ano de 2003, no intuito de coibir a prática irregular de trabalho, o Ministério do Trabalho e Emprego criou um cadastro com os empregadores que, porventura, tenham mantido trabalhadores em condições análogas à de escravo. Assim, uma lista - convencionalmente denominada Lista Suja - contendo os nomes desses empregadores, é periodicamente divulgada com base em Portarias do Poder Executivo. Atualmente, a norma que autoriza sua elaboração e divulgação é a Portaria Interministerial MTPS/MMIRDH 4, de 11 de maio de 2016, publicada no dia 13 de maio desse mesmo ano (MATSUMOTO; DUARTE, 2017).

A divulgação do Cadastro de Empregadores que tenham submetido trabalhadores a condições análogas à de escravo, no entanto, não é pacífica. Recentemente, o Ministério do Trabalho divulgou nota oficial informando que não divulgará o Cadastro por tempo indeterminado, "por considerar que a Portaria que hoje regula a formação da lista, ...não garante aos cidadãos instrumentos de efetivo exercício dos direitos constitucionalmente assegurados ao contraditório e à ampla defesa, bases sob as quais se firma qualquer nação civilizada" (BRASIL, 2017a).

Replicando a informação contida na nota divulgada pelo Ministério do Trabalho, o Ministério Público do Trabalho informou que o contraditório e a ampla defesa não são violados pela publicação da "lista suja". Pelo contrário, a inclusão do nome do infrator no cadastro somente se efetiva após a decisão final e exauriente de procedência do 
referido auto de infração (BRASIL, 2017b).

Analisando a decisão prolatada na Ação Direta de Inconstitucionalidade 5.209/DF, proposta pela Associação Brasileira de Incorporadoras Imobiliárias (Abrainc), o mesmo Supremo Tribunal Federal que concedeu em 2014, liminar suspendendo a divulgação da referida lista, fez constar expressamente que eventual questionamento acerca da violação aos direitos de defesa foram integralmente sanados pela Portaria $\mathrm{n}^{\circ}$ 4/2016, publicada em maio de 2016 e atualmente em vigor.

Nesse intervalo, o Ministério Público do Trabalho propôs Ação Civil Pública com pedido liminar requerendo a União seja compelida a divulgar referida lista. A liminar foi concedida em decisão prolatada no dia 19 de dezembro de 2016, determinando que a União volte a publicar a "lista suja" no período de até 30 dias.

No dia 07 de março de 2017, em decisão polêmica, o Ministro do Tribunal Superior do Trabalho suspendeu, por 120 dias, a divulgação das listas, logo após dois recursos do Governo Federal, onde se requeria a "reformulação e aperfeiçoamento" da portaria que a criaria. A Decisão levou a entidade Conectas a levar o caso ao Conselho de Direitos Humanos da Organização das Nações Unidas, em Genebra.

Muito embora tutela tenha sido revertida uma semana depois, após um pedido liminar feito pelo Ministério Público do Trabalho, a entidade insistiu na denúncia, sob o fundamento de que a suspensão do documento apenas beneficiaria os setores corporativos envolvidos com atividades de exploração da mão de obra (CHADE, 2017).

Com a divulgação do referido Cadastro, os direitos de defesa não seriam violados, pois estariam assegurados em todo o processo administrativo até decisão irrecorrível de procedência do auto de infração. 
O direito à liberdade de informação seria garantido, conforme previsto constitucionalmente, ao passo que a classe mais vulnerável estaria sendo beneficiada, em detrimento dos setores corporativos.

No estado de São Paulo, política semelhante foi adotada, mediante a proposição do Projeto de Lei ${ }^{\circ}$ 1.034/2011, transformado posteriormente na Lei $\mathrm{n}^{\circ}$ 14.946/2013. Segundo o texto estabelecido na norma, as empresas que se utilizam do trabalho em condições análogas à de escravo serão autuadas e fechadas. Além da autuação e fechamento, os donos ficarão impedidos de exercer quaisquer atividades do mesmo ramo de produção ou abrir nova firma no setor pelo período de dez anos (SÃO PAULO, 2013).

Não se trata, portanto, de análise superficial acerca da responsabilidade exclusiva das empresas que exploram diretamente a mão de obra. Muitas vezes, estas empresas também estão subordinadas, pois fazem parte de uma cadeia produtiva. Para maior eficácia no combate à exploração, necessária se faz a compreensão de como se dá a distribuição de tarefas nas cadeias produtivas, para que, logo após, seja verificada a extensão da responsabilidade às grandes empresas.

\section{ANÁLISE DA RESPONSABILIDADE DAS GRANDES MAGAZINES DENTRO DAS CADEIAS PRODUTIVAS}

Pode-se afirmar que os setores de produção, sobretudo os setores têxteis e de confecções, sofreram grandes mudanças no cenário global. Até a década de 80, esses setores não sofriam grandes variações entre as temporadas, que por sua vez, eram bem definidas: primavera-verão e outono-inverno. Grande parte da matéria-prima era trabalhada em lugares relativamente próximos ao consumidor final. 
Como a atividade era determinada pela lei da oferta e da procura, os varejistas se preocuparam em ampliar a gama de produtos ofertados, buscando combinações modernas revestidas de diferenciação. Assim, dois fatores foram fundamentais para a busca de alternativas de produção nos países subdesenvolvidos e emergentes: o aumento da competitividade e o elastecimento dos ciclos de produção.

Com o objetivo de reduzir os custos de produção e da mão de obra, as produções foram deslocadas para outros países. Assim, o produto final é desenhado e comercializado nos países desenvolvidos, ao passo que sua fabricação se dá nos países subdesenvolvidos. Trata-se de um processo contínuo, onde, grandes empresas remontam e distribuem suas tarefas em função das estratégias e do grau de abertura econômica dos países (JACQUES, 2015, p. 135).

Essa política de interesses, todavia, demonstra que as empresas subcontratadas não possuem autonomia, uma vez que estão subordinadas a grandes empresas. A consequência disso é a formação de um sistema produtivo totalmente hierarquizado, onde a valoração das forças produtivas (fábricas, máquinas e oficinas) está diretamente relacionada com o nível de desenvolvimento dos países de localização (PITACAS, 2017).

Um dos eixos do estudo das cadeias produtivas estrutura-se com base na capacidade de responsabilização dos que atuam em constante exploração e violação dos direitos e garantias dos trabalhadores. A ramificação da cadeia produtiva tem ocasionado a subcontratação de empresas especializadas, sobretudo, com a contratação de trabalhadores em situação irregular e análoga à escravidão. ${ }^{15}$

15 Essa ocorrência é difundida entre as mais variadas multinacionais varejistas, sobretudo nas áreas da confecção e construção civil. Vejam se exemplos de grandes empresas nacionais, como a Zara, única representante brasileira da empresa multinacional Inditex. 
Todavia, muito embora a exploração não ocorra de forma direta pelos grandes magazines e sim pelas empresas subcontratadas, responsáveis pelas demandas de massa, um questionamento merece ser feito: seria factível que as empresas multinacionais fossem responsabilizadas pela exploração que ocorre nas cadeias de produção de seus produtos?

Analisando decisão proferida no Caso Zara, a responsabilização das grandes empresas encontra bases sólidas. O cerne da questão consistia na legalidade da intermediação da maufatura dos produtos comercializados entre a empresa AHA ${ }^{16}$ Indústria e Comércio Ltda e Zara Brasil Ltda. Segundo a Zara Brasil, a primeira seria a real contratante dos trabalhadores encontrados em situação precária de trabalho. Constatou-se, todavia, ser a Zara a adquirente de mais de $90 \%$ de toda a produção da Aha, caracterizando-se, na prática, um monopsônio (ÍNTEGRA..., 2014).

O provedor, a empresa AHA, enviava as peças piloto para a empresa Inditex, na Espanha, após a aprovação por uma gerente da Zara no Brasil. Somente após o aval da empresa matriz, o pedido oficial e as etiquetas eram emitidas, demonstrando a dependência econômica da empresa AHA à empresa Zara na cadeia de produção. Na investigação proposta pelo MTE/SRTE (SP), comprovou-se que a AHA estava subordinada economicamente à Inditex. ${ }^{17}$ Segundo o auditor Luís Alexandre Faria, comandante das investigações, a Zara faz de tudo para não aparecer no processo (PYL; HASHIZUME, 2011).

16 As investigações realizadas em 2011 pelo MTE/SRTE demonstram que um dos provedores da Zara Brasil, a empresa AHA, subcontratava oficinas de costura que não cumpriam os direitos fundamentais dos trabalhadores. Comprovou-se que a AHA estava subordinada economicamente à Inditex, empresa multinacional que, além da marca Zara, é composta por outras, como Pull\&Bear, Massimo Dutti, Bershka, Stradivarius, Oysho, Zara Home e Uterqüe.

17 Semelhante ao modelo português, o provedor AHA se enquadrava na concepção de parasita da cadeia produtiva, pois não possuía um quadro de trabalhadores compatível com a produção que the era dirigida. Os parasitas, portanto, seriam personagens que atuam na cadeia de produção através de atividades meio, isto é, sem participar do processo de produção do produto principal. Por exemplo, serviço de entrega. 
A visibilidade pública do Caso da Zara ocorreu em 2011, após a divulgação televisiva das condições de trabalho nas grandes confecções. Uma equipe de reportagem acompanhou as operações de fiscalização do Ministério Público do Trabalho em algumas empresas clandestinas de São Paulo, que produziam peças de roupas para a marca Zara (BAND NOTÍCIAS, 2011). O fluxograma abaixo demonstra a estrutura produtiva da Zara Brasil naquele momento.

Gráfico 3 - Estrutura produtiva da Zara no ano de 2011

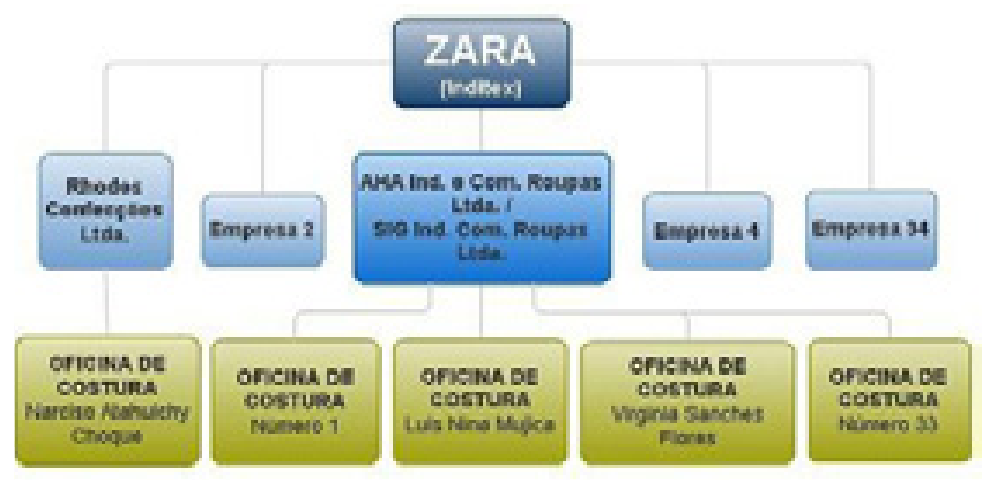

Fonte: Pyl e Hashizume (2011).

Durante o período de fiscalização, observou-se que, muito embora a empresa AHA tenha crescido em faturamento de produção para a Zara, a empresa reduziu drasticamente o número de empregados contratados diretamente, indicando o aumento dos processos de quarteirização da mão de obra. ${ }^{18}$ Observou-se, igualmente, que não importa quão grande seja a

18 Dias (1998) afirma que a terceirização é uma —-ferramenta de gestãol ou uma —filosofia da administraçãol que permite à empresa focar em sua atividade principal, contratando outras empresas para atividades que não contribuam diretamente com a -razão de serll da organização. Nas correntes contemporâneas da administração, a quarteirização refere-se à contratação de uma terceira empresa - geralmente da área de logísitca - para administrar as empresas terceirizadas pela firma tomadora de serviços (conhecido como 
cadeia produtiva, as empresas que a originam detém a responsabilidade social e legal quando, por si mesmas, subcontratam empresas com o objetivo de aumentar a produção e de reduzir custos.

Em uma análise sistemática das cadeias produtivas, conclui-se que a exploração de mão de obra nas empresas subcontratadas se mostra como o efeito e consequência do modelo de mercado exercido pelas grandes empresas. Desse modo, demonstra-se cabível a responsabilização direta das grandes empresas dentro das cadeias produtivas pelos trabalhadores escravizados.

\section{CONCLUSÃO}

A presente pesquisa teve o intuito de refletir criticamente acerca de possível responsabilização dos grandes magazines pela exploração de mão de obra que ocorre dentro das cadeias de produção de seus produtos.

De modo preambular, foi realizado breve estudo acerca do modelo escravagista arcaico. Verificou-se que, muito embora o trabalho fosse realizado mediante coerção aberta e violência em potencial, o processo de alienação utilizado pelos colonos, formou nos colonizados, sinal de civilidade e libertação.

Observou-se que, mesmo após um século da abolição da escravatura no Brasil, a exploração laboral extremada continua presente no país. Ao contrário do modelo escravagista arcaico, o modelo capitalista passa a reger as relações de exploração entre empregado e empregador, atribuindo valor ao potencial de trabalho e ao tempo utilizado para desenvolver determinada atividade. Dessa forma, no mercado de trabalho

\footnotetext{
4PL - fourth-party logistics). Mas esse não é o sentido da quarteirização na cadeia produtiva da Inditex. Nesse caso, a quarteirização é a transferencia de serviços para uma terceira empresa, contratada pela provedora AHA, algo como a terceirização da terceirização.
} 
capitalista, a mão de obra passa a ser valorada e sopesada com base no binômio força de trabalho $\mathrm{x}$ tempo de produção.

Posteriormente, refletiu-se acerca dos modos de manifestação do trabalho em condições análogas à de escravo na sociedade contemporânea. Verificou-se que o trabalho forçado e o trabalho em condições degradantes são subespécies do gênero trabalho em condições análogas à de escravo. Inclusive o trabalho infantil, como subespécie do trabalho forçado ou em condições degradantes, compõe esse núcleo.

Com base nos dados estatísticos analisados, verificou-se que os diversos dispositivos de proteção ao trabalhador, que intentam de evitar as práticas abusivas e ilegais de exploração da mão de obra, se mostram ineficazes. Essa ineficácia se dá pela constante redução no número de fiscalizações, ocasionada, sobretudo, pela insuficiência dos auditores fiscais do trabalho em campo.

Para atingir satisfatoriamente um patamar de efetivo combate à escravidão, não basta a mera positivação dos dispositivos protetivos. A atuação dos órgãos nacionais e internacionais, tais como a Organização Internacional do Trabalho, Justiça do Trabalho e o Ministério Público do Trabalho e Emprego, se mostram essenciais para a efetiva proteção do trabalhador e para a real abolição do trabalho análogo ao de escravo, desde que exercida de forma integrada.

As políticas restritivas, tais como a "lista suja" e a Lei $\mathrm{n}^{0}$ 14.946/2013, devem ser incentivadas por todos os envolvidos no processo de erradicação e combate à exploração da mão de obra pelas grandes magazines. Estas, de modo incontroverso, devem responder objetivamente por quaisquer ilegalidades dentro da cadeia de produção de seus produtos, uma vez que a subcontratação de empresas, visando diminuir os custos e majorar os lucros enseja, por sua própria natureza, 
a exploração da mão de obra, consoante o atual modelo capitalista de produção.

A subsistência dessa mácula social nos dias atuais demonstra a necessidade de permanente e efetiva busca por condições laborais dignas, nas quais devem ser respeitadas condições mínimas de higiene, de saúde e de proteção ao trabalhador. As condições de emprego e renda devem ser asseguradas, no intuito de que as famílias tenham condições de agir em resgate de sua própria dignidade.

\section{REFERÊNCIAS}

\section{AGÊNCIA BRASIL. Trabalho escravo no mercado da moda é} tema de debate no Rio de Janeiro. 2017. Disponível em: <https:// istoe.com.br/trabalho-escravo-no-mercado-da-moda-e-tema-dedebate-no-rio-de-janeiro/>. Acesso em: 27 jan. 2017.

ALJAZEERA. Brazil: slaves to fashion. 2016. Disponível em: <http:// www.aljazeera.com/programmes/latin-america-investigates/2016/12/ brazil-slaves-fashion-161229063654192.html>. Acesso em: 24 jul. 2017.

\section{BAND NOTÍCIAS. Zara reconhece trabalho escravo em} confecção. 2011. Disponível em: <http://noticias.band.uol.com.br/ cidades/noticia/?id=100000450252>. Acesso em: 2 jan. 2017.

BIGNANI, Renato. Trabalho escravo contemporâneo: o sweating system no contexto brasileiro como expressão do trabalho forçado urbano. Disponível em: < https://www.sinait.org.br/arquivos/artigos/ artigo19216c4627d24e2563a4335ceb2c9469.pdf >. Acesso em: 15 fev. 2017.

BRAGA, Luã. O trabalho escravo no século XXI. 2014. Disponível em: $<$ http:/www.feedbackmag.com.br/o-trabalho-escravo-no-seculo- 
xxi/>. Acesso em: 23 mar. 2016.

BRASIL. Decreto-Lei n ${ }^{\circ} 2.848$, de 7 de dezembro de 1940. In:

. Vade mecum RT. 2. ed. São Paulo: Revista dos Tribunais, 2008. p. 493-494.

BRASIL. Ministério do Trabalho. Ministério do trabalho se posiciona sobre empresas autuadas em trabalho análogo à escravidão. 2017a. Disponível em: < http://trabalho.gov.br/ noticias/4209-ministerio-do-trabalho-se-posiciona-sobre-empresasautuadas-em-trabalho-analogo-a-escravidao>. Acesso em: 5 jul. 2017.

BRASIL. Ministério Público do Trabalho. Necessária publicidade à lista suja do trabalho escravo. 2017b. Disponível em: $<$ http://portal. mpt.mp.br/wps/portal/portal_mpt/mpt/sala-imprensa/mpt-noticias $>$. Acesso em: 5 jul. 2017.

BRASIL. Tribunal Regional do Trabalho (10. Região). Impunidade estimula trabalho escravo no país. 2014. Disponível em: < https:// trt-10.jusbrasil.com.br/noticias/113040693/impunidade-estimulatrabalho-escravo-no-pais $>$. Acesso em: 5 jul. 2017.

BRITO FILHO, José Claudio Monteiro de. Trabalho com redução do homem à condição análoga à de escravo e dignidade da pessoa humana. Disponível em: $<$ http://pgt.mpt.gov.br/publicacoes/escravo/dignidadetrabalhoescravo.pdf $>$. Acesso em: 5 jul. 2017.

CANAL RURAL. Casos de trabalho escravo caíram em 2016. 2017. Disponível em: < http://www.canalrural.com.br/noticias/ noticias/casos-trabalho-escravo-caem-2016-65795>. Acesso em: 25 jul. 2017.

CHADE, Jamil. Brasil é denunciado à ONU após TST vetar 'lista suja' do trabalho escravo. Estadão, São Paulo, 20 mar. 2017. Disponível em: <http://economia.estadao.com.br/noticias/ geral,brasil-e-denunciado-a-onu-apos-tst-vetar-lista-suja-do-trabalho- 
escravo,70001707090>. Acesso em: 28 jul. 2017.

DIAS, Reinaldo. Tópicos atuais em administração: quarteirização.

São Paulo: Alínea, 1998.

FANON, Frantz. Os condenados da terra. 2. ed. Rio de Janeiro: Civilização Brasileira, 1979.

\section{G1. $N^{0}$ de trabalhadores resgatados cai $96 \%$ com fiscalização} menor no CE. 2017. Disponível em: <http://g1.globo.com/ceara/ noticia/2017/01/n-de-trabalhadores-resgatados-cai-96-comfiscalizacao-menor-no-ce.html>. Acesso em: 24 jul. 2017.

GANDRA, Alana. Com menos fiscalizações, casos de trabalho escravo caem em 2016. 2017. Disponível em: $<$ http://agenciabrasil. ebc.com.br/direitos-humanos/noticia/2017-01/com-menosfiscalizacoes-casos-de-trabalho-escravo-caem-em-2016-diz-Pastoral $>$. Acesso em: 24 jul. 2017.

GOSDAL, Thereza Cristina. Dignidade do trabalhador: um conceito construído sob o paradigma do trabalho decente e da honra. São Paulo: LTR, 2007.

ÍNTEGRA da sentença judicial em que Zara é responsabilizada por escravidão. 2014. Disponível em: $<$ http://reporterbrasil. org.br/2014/04/integra-da-sentenca-judicial-em-que-zaraeresponsabilizada-por-escravidao/>. Acesso em: 12 jan. 2015.

JACQUES, Caroline da Graça. Trabalho decente e responsabilidade social empresarial nas cadeias produtivas globais: o modelo fast fashion em Portugal e no Brasil. 2015. Tese (Doutorado em Sociologia Política) - Universidade Federal de Santa Catarina, Florianópolis, 2015. Disponível em: <https://repositorio.ufsc.br/ handle/123456789/135124>. Acesso em: 6 abr. 2017.

LIMA, Benedito; SURKAMP, Luize. Erva mate: erva que escraviza. 
Fortaleza: La Barca, 2012.

MAIA, Samantha. Renner está envolvida com trabalho escravo. 2014. Disponível em: <http://www.cartacapital.com.br/revista/828/ renner-esta-envolvida-com-trabalho-escravo-1352.html>. Acesso em: 25 jul. 2017.

MARQUESE, Rafael de Bivar. A dinâmica da escravidão no Brasil: resistência, tráfico negreiro e alforrias, séculos XVII a XIX. Novos estudos-CEBRAP, São Paulo, n. 74, p. 107-123, 2006.

MARX, Karl. Contribuição para a crítica à economia política. São Paulo: Mandacaru, 1989.

MARX, Karl. Trabalho assalariado e capital \& salário, preço e lucro. São Paulo: Expressão Popular, 2010.

MATSUMOTO, Jorge Gonzaga; DUARTE, Vinicius Franco. Regras da "lista suja" do trabalho escravo necessitam de uma faxina.

Consultor Jurídico, São Paulo, jan. 2017. Disponível em: < https:// www.conjur.com.br/2017-jan-27/regras-lista-suja-trabalho-escravonecessitam-faxina >. Acesso em: 28 jul. 2017.

MELLO, Alessandra. Chacina de Unaí completa 13 anos sem a prisão dos mandantes do crime. 2017. Disponível em: $<\mathrm{https}: / \mathrm{www}$. em.com.br/app/noticia/politica/2017/01/28/interna_politica,843070/ chacina-de-unai-completa-13-anos-sem-prisao-dos-mandantes.shtml $>$. Acesso em: 27 jul. 2017.

NETTO, José Paulo; BRAZ, Marcelo. Economia política: uma introdução crítica. São Paulo: Cotez, 2008.

NUNES, Flávio Filgueiras. A persistência no trabalho escravo no Brasil. 2005. Trabalho de Conclusão de Curso (Graduação em Direito) Faculdade Vianna Junior, Juiz de Fora, 2005. 
ORGANIZAÇÃO INTERNACIONAL DO TRABALHO - OIT. Não ao trabalho forçado. Genebra: OIT, 2001. Disponível em: <http:// www.oit.org.br/sites/default/files/topic/forced_labour/pub/nao trabalho_forcado_311.pdf>. Acesso em: 5 jul. 2017.

PITACAS, José Alberto. Deslocalização de Empresas. Disponível em: $<$ http://psfanzeres.no.sapo.pt/Estudos/desloca_emp.pdf $>$. Acesso em: 5 jul. 2017.

PYL, Bianca; HASHIZUME, Maurício. Roupas da Zara são fabricadas com mão de obra escrava. Repórter Brasil, São Paulo, ago. 2011. Disponível em: <http://reporterbrasil.org.br/2011/08/ roupas-da-zara-saofabricadas-com-mao-de-obra-escrava/ $>$. Acesso em: 6 abr. 2017

RIBEIRO, Victor. Trabalho escravo urbano no brasil transforma sonho de bolivianos em pesadelo. 2017. Disponível em: $<\mathrm{http}: / / \mathrm{m}$. radioagencianacional.ebc.com.br/direitos-humanos/audio/2017-01/ trabalho-escravo-urbano-no-brasil-transforma-sonho-de-bolivianosem>. Acesso em: 8 jul. 2017.

RUSCHE, Georg; KIRCHEHEIMMER, Otto. Punição e estrutura social. Tradução de Gizlene Neder. 2. ed. Rio de Janeiro: Revan; ICC, 2004.

SÃO PAULO. Lei no 14.946, de 28 de janeiro de 2013. Dispõe sobre a cassação da inscrição no cadastro de contribuintes do Imposto sobre Operações Relativas à Circulação de Mercadorias e sobre Prestações de Serviços de Transporte Interestadual e Intermunicipal e de Comunicação - ICMS, de qualquer empresa que faça uso direto ou indireto de trabalho escravo ou em condições análogas. Disponível em: $<$ https://www.al.sp.gov.br/propositura/?id=1043074>. Acesso em: 28 jul. 2017.

SCHERNOVSKI, Valdeci. Trabalho escravo contemporâneo. 2014. 
Disponível em: <http://advaldeci.jusbrasil.com.br/artigos/111749665/ trabalho-escravo-contemporaneo $>$. Acesso em: 23 maio 2016.

SINAIT. Trabalho escravo contemporâneo existe. 2016. Disponível em: < https://www.sinait.org.br/site/noticiaView/12951/trabalhoescravo-contemporaneo-existe> . Acesso em: 25 jul. 2017.

VELASCO, Clara; REIS, Thiago. $\mathbf{N}^{\mathbf{0}}$ de libertados em trabalho análogo ao escravo cai $34 \%$ em 1 ano; total é o menor desde 2000. 2017. Disponível em: $<$ https://g1.globo.com/economia/noticia/n-delibertados-em-trabalho-analogo-ao-escravo-cai-34-em-1-ano-total-e-omenor-desde-2000.ghtml>. Acesso em: 25 jul. 2017.

Como citar: SILVA, Alexandre Antônio Bruno da; SILVEIRA, Whenry Hawlysson Araújo. Análise do trabalho escravo nas grandes magazines: uma leitura moderna acerca do novo modo de exploração. Scientia Iuris, Londrina, v. 22, n. 1, p.223-257, mar. 2018. DOI: 10.5433/2178-8189.2018v22n1p223. ISSN: 2178-8189.

Recebido em: 19/07/2017

Aprovado em: 22/02/2018 